This article was published in Biofouling, 30 (6), 675-683, 2014

http://dx.doi.org/10.1080/08927014.2014.904294

\title{
The ability of an antimicrobial agent to penetrate a biofilm is not correlated with its killing or removal efficiency
}

\author{
Paula A. Araújo, Filipe Mergulhão, Luís Melo and Manuel Simões* \\ LEPABE, Faculty of Engineering, Department of Chemical Engineering, University of Porto, \\ Porto, Portugal
}

(Received 8 January 2014; accepted 7 March 2014)

The penetration ability of 12 antimicrobial agents, including antibiotics and biocides, was determined against biofilms of $B$. cereus and $P$. fluorescens using a colony biofilm assay. The surfactants benzalkonium chloride (BAC) and cetyltrimethyl ammonium bromide (CTAB), and the antibiotics ciprofloxacin and streptomycin were of interest due to their distinct activities. Erythromycin and CTAB were retarded by the presence of biofilms, whereas ciprofloxacin and $B A C$ were not. The removal and killing efficacies of these four agents was additionally evaluated against biofilms formed in microtiter plates. The most efficient biocide was CTAB for both bacterial biofilms. Ciprofloxacin was the best antibiotic although none of the selected antimicrobial agents led to total biofilm removal and/or killing. Comparative analysis of the results obtained with colony biofilms and microtiter plate biofilms show that although extracellular polymeric substances and the biofilm structure are considered a determining factor in biofilm resistance, the ability of an antimicrobial agent to penetrate a biofilm is not correlated with its killing or removal efficiency. Also, the results reinforce the role of an appropriate antimicrobial selection as a key step in the design of disinfection processes for biofilm control.

Keywords: antimicrobial resistance; Bacillus cereus; biofilm control; Pseudomonas fluorescens; disinfection; diffusional limitations

\section{Introduction}

A biofilm is commonly defined as a microbial community with cells irreversibly attached to a substratum or attached to each other, and embedded in a matrix of extracellular polymeric substances (EPS) (Donlan \& Costerton 2002). EPS protects bacteria from environ-mental adversities (Jefferson 2004). In all industries, especially in the food industry, the proliferation of microorganisms is very common even when manufacturers diligently follow all the necessary contingency plans (Araújo et al. 2011). The main objective of microbial control is to eliminate microorganisms or reduce their numbers to acceptable levels, as well as to prevent and control the formation of biological deposits attached to equipment surfaces (Maukonen et al. 2003). Currently, there is no control strategy capable of entirely eradicating biofilms (Simões et al. 2010). There is a need to find new strategies to manage antimicrobial resistance (Lee et al. 2013; Traba et al. 2013). 
Resistance is the ability to withstand antimicrobial treatments. Russell (1999) and Chapman (2003) documented three types of resistance: intrinsic resistance, eg the Gram-negative lipopolysaccharide layer (McDonnell \& Russell 1999); acquired resistance, eg manipulated resistance mediated by plasmids; and adaptive resistance, eg exposure to sub-lethal concentrations of an antimicrobial agent that selects for mutation, confer-ring resistance to that agent or others of the same type (cross-resistance). The way microorganisms develop resistance is not well understood. However, biofilm formation is a case of adaptive resistance and is considered a microbial survival strategy, enabling them to be $10-1,000$-fold more resistant to antimicrobial agents than their free-floating equivalents (Mah \& O'Toole 2001; Nikolaev 2004; Araújo et al. 2012). Antimicrobial resistance is multi-factorial and usually does not depend on one specific mechanism only (Maillard 2002; Drenkard 2003). When biofilms are exposed to antimicrobial agents, they present specific survival strategies. Biofilm cells are physiologically distinct from their planktonic counterparts by having specific resistance genes that express protective factors such as multi-drug efflux pumps, stress response regulons and different cell physiognomies (Davies 2003). Moreover, they often present decreased respiration and growth/replication rates, despite having higher cell densities. Embedded cells are capable of communicating through quorum sensing, and the existence of persister cells enables them to survive (Simões et al. 2011). Biofilm cells are protected by the EPS they produce. The functions of EPS include enabling the biofilm to withstand shear forces, dehydration and chemical attacks (Flemming 2007). EPS enhances robustness and survival of the biofilm microorganisms on a substratum by serving as a chemically reactive diffusional transport barrier slowing down the penetration of antimicrobial agents. This matrix reinforces biofilm attachment to the substratum and promotes its mechanical stability (Bryers 1992, 1994). Moreover, it is where the convective and diffusional transport to the biofilm of oxygen, nutrients, and other substances takes place (Stewart 2003). The composition and architecture of EPS influences how oxygen, nutrients and cell excreted products are transported (Andersson et al. 2009). The biofilm constituents may act as an adsorbent or reactant, thus chemically impairing diffusion, and its structure (porosity and tortuosity) may physically reduce transport (Russell et al. 1997; Costerton 1999; Melo 2005; Flemming \& Wingender 2010; Stewart 2012).

In order to plan a disinfection procedure it is important to select a suitable antimicrobial agent with an appropriate effectiveness against the contaminants (Simões et al. 2010; Araújo et al. 2013). The objective of this study was to understand the role of biofilms in the effectiveness of antimicrobial agents, with a specific focus on the selection of suitable chemical compounds capable of passing the EPS barrier and killing and removing the bio-film embedded cells of $B$. cereus and $P$. fluorescens. These bacteria are ubiquitous in industrial systems, causing numerous process and end product quality problems (Lindsay et al. 2002; Simões et al. 2008). The production of extracellular enzymes by these bacteria results in food spoilage (Lindsay et al. 2002; Teh et al. 2011, 2012). Moreover, they can represent a significant proportion of the contaminant biofilm microflora of constitutive dairy plants (Sharma \& Anand 2002; Dogan \& Boor 2003; Kreske et al. 2006; Wijman et al. 2007).

\section{Materials and methods}

\section{Microorganisms and culture conditions}

The bacteria used in this work were $P$. fluorescens ATCC $13525^{\top}$ and a $B$. cereus strain isolated from a disinfectant solution and identified by 16S rRNA gene sequencing (Simões et al. 2008). 
Bacterial growth conditions were $30 \pm 3^{\circ} \mathrm{C}$ and $\mathrm{pH} 7$, with glucose as the main carbon source. The culture medium consisted of $5 \mathrm{~g} \mathrm{I}^{-1}$ of glucose, $2.5 \mathrm{~g} \mathrm{l}^{-1}$ of pep-tone and $1.25 \mathrm{~g} \mathrm{l}^{-1}$ of yeast extract, in phosphate buffer (pH 7, 25 mM) (Simões, Cleto, et al. 2007). All the constituents of the culture medium were purchased from Merck (VWR, Carnaxide, Portugal). Bacterial suspensions were prepared by gently removing a small portion of bacteria from a solid medium, and diluting it in a one flask (Duran, VWR, Carnaxide, Portugal) containing $250 \mathrm{ml}$ of sterile culture medium. This bacterial suspension was incubated overnight (16 h) at the given temperature, with agitation (120 rpm). After the growth period, the suspension was washed with phosphate buffer in two consecutive steps of centrifugation $(3,999 \mathrm{~g}, 10 \mathrm{~min}$ ) in an Eppendorf centrifuge 5810R (Göttingen, Germany), and resuspended in phosphate buffer (20 $\mathrm{mM}$ ), in order to obtain a final bacterial concentration of $1 \times 10^{9}$ cells $\mathrm{ml}^{-1}$.

\section{Antimicrobials}

The 12 antimicrobials used throughout the experiments (Table 1) were cetyltrimethyl ammonium bromide (CTAB), benzalkonium chloride (BAC), sodium hypo-chlorite, ethanol, hydrogen peroxide, streptomycin, and tetracycline, all obtained from Sigma-Aldrich (Sintra, Portugal). Benzyl dimethyl dodecyl ammonium chloride (BDMDAC) was obtained from Merck (VWR). Ciprofloxacin was acquired from Fluka (Sintra, Portugal). Chlorine dioxide was obtained from TwinOxide ${ }^{\circledR}$ (Salmon \& Cia. Lda, Lisbon, Portugal) and isopropanol and erythromycin were purchased from AppliChem (VWR, Carnaxide, Portugal). When possible, the com-pounds were used as commonly sold (a). Some amounts of antimicrobial were previously optimized to obtain a detectable inhibition halo (b), and others were used at the reported minimum inhibitory concentrations (MIC)(c) (Spangler et al. 1996; Turnbull et al. 2004).

Table 1. Antimicrobial agents plus respective $S$. aureus inhibition halos, and percentage retardation caused by the presence of $B$. cereus and $P$. fluorescens biofilms.

\begin{tabular}{|c|c|c|c|c|c|}
\hline \multirow[b]{2}{*}{ Antimicrobial agents } & \multicolumn{3}{|c|}{ B. cereus } & \multicolumn{2}{|c|}{ P. fuorescens } \\
\hline & Mass ( $\mu \mathrm{g})$ & $\begin{array}{l}\text { Inhibition halos } \\
\qquad(\mathrm{mm})\end{array}$ & Retardation (\%) & Inhibition halos (mm) & Retardation (\%) \\
\hline \multicolumn{6}{|l|}{ Alcohols } \\
\hline Ethanol $^{\mathrm{a}}$ & 8,242 & $12 \pm 1.3$ & $12 \pm 7.0$ & $13 \pm 0.96$ & $9.3 \pm 2.5$ \\
\hline Isopropanol $^{\mathrm{a}}$ & 11,700 & $2.3 \pm 0.47$ & $70 \pm 8.8$ & $4.3 \pm 2.1$ & $52 \pm 22$ \\
\hline \multicolumn{6}{|l|}{ Oxidizing agents } \\
\hline Sodium hypochlorite ${ }^{\mathrm{b}}$ & $543(\mathrm{Cl})$ & $4.6 \pm 0.50$ & $5.0 \pm 0.45$ & $4.7 \pm 0.10$ & $1.9 \pm 3.1$ \\
\hline Chlorine dioxide $^{a}$ & 74 (Cl) & $5.3 \pm 0.84$ & $32 \pm 12$ & $3.0 \pm 0.71$ & $47 \pm 13$ \\
\hline Hydrogen peroxide ${ }^{\mathrm{a}}$ & 500 & $0.0 \pm 0.0$ & $100 \pm 0.0$ & $0.0 \pm 0.0$ & $100 \pm 0.0$ \\
\hline \multicolumn{6}{|l|}{ Surfactants } \\
\hline $\mathrm{BAC}^{\mathrm{b}}$ & 350 & $18 \pm 1.3$ & $0.11 \pm 0.07$ & $18 \pm 0.25$ & $0.0 \pm 0.0$ \\
\hline $\mathrm{BDMDAC}^{\mathrm{b}}$ & 350 & $19 \pm 0.25$ & $15 \pm 1.1$ & $19 \pm 0.10$ & $13 \pm 0.54$ \\
\hline CTAB $^{\mathrm{b}}$ & 350 & $0.0 \pm 0.0$ & $100 \pm 0.0$ & $0.0 \pm 0.0$ & $99 \pm 1.6$ \\
\hline \multicolumn{6}{|l|}{ Antibiotics } \\
\hline Ciprofloxacin $^{\mathrm{c}}$ & 5 & $20 \pm 1.0$ & $0.0 \pm 0.0$ & $24 \pm 0.50$ & $0.0 \pm 0.0$ \\
\hline Erythromycin $^{\mathrm{c}}$ & 15 & $14 \pm 0.05$ & $14 \pm 0.32$ & $12 \pm 0.50$ & $28 \pm 3.1$ \\
\hline Streptomycin ${ }^{\mathrm{c}}$ & 10 & $0.0 \pm 0.0$ & $100 \pm 0.0$ & $3.4 \pm 0.05$ & $40 \pm 0.89$ \\
\hline Tetracycline ${ }^{\mathrm{c}}$ & 30 & $22 \pm 0.94$ & $6.9 \pm 3.9$ & $24 \pm 0.47$ & $12 \pm 1.8$ \\
\hline
\end{tabular}

${ }^{2}$ Commonly available/standard concentration.

Optimized concentration.

${ }^{\circ} \mathrm{MIC}$.

Abbreviation: $\mathrm{Cl}$, chlorine.

Means \pm SD are presented. 


\section{Biofilm colony formation and antimicrobial penetration tests}

Biofilm colonies were developed according to the method of Anderl et al. (2000) and Singh et al. (2010). Biofilms were grown in sterile Mueller-Hinton agar plates $\left(24 \mathrm{~h}, 30 \pm 3^{\circ} \mathrm{C}\right)$. A volume of $40 \mu \mathrm{l}$ of cell suspension of $B$. cereus or $P$. fluorescens was placed on a $13 \mathrm{~mm}$ polycarbonate membrane, pore size $0.2 \mu \mathrm{m}$ (Merck, Millipore, Carnaxide, Portugal) to produce bio-film colonies. Afterwards, the membranes with biofilms were transferred to a fresh plate containing the same growth medium, seeded with Staphylococcus aureus CECT 976 at a McFarland standard of 0.5 (Anderl et al. 2000; Singh et al. 2010). Another polycarbonate mem-brane was placed on top of the biofilm so that the sterile discs (Biochemica, VWR, Carnaxide, Portugal) were not in direct contact with the biofilms (Figure 1). The antimi-crobial discs were impregnated with a $15 \mu \mathrm{l}$ drop containing the different antimicrobials used, providing the amount per disc described in Table 1. The negative controls contained a $15 \mu \mathrm{l}$ drop of sterile distilled water and the positive controls were obtained in the absence of bio-film. The plates were incubated for $24 \mathrm{~h}$ at $30 \pm 3^{\circ} \mathrm{C}$ before assessment of the inhibition halos. The positive controls were taken as $100 \%$ penetration and used to calculate the penetration rates when biofilms were present.

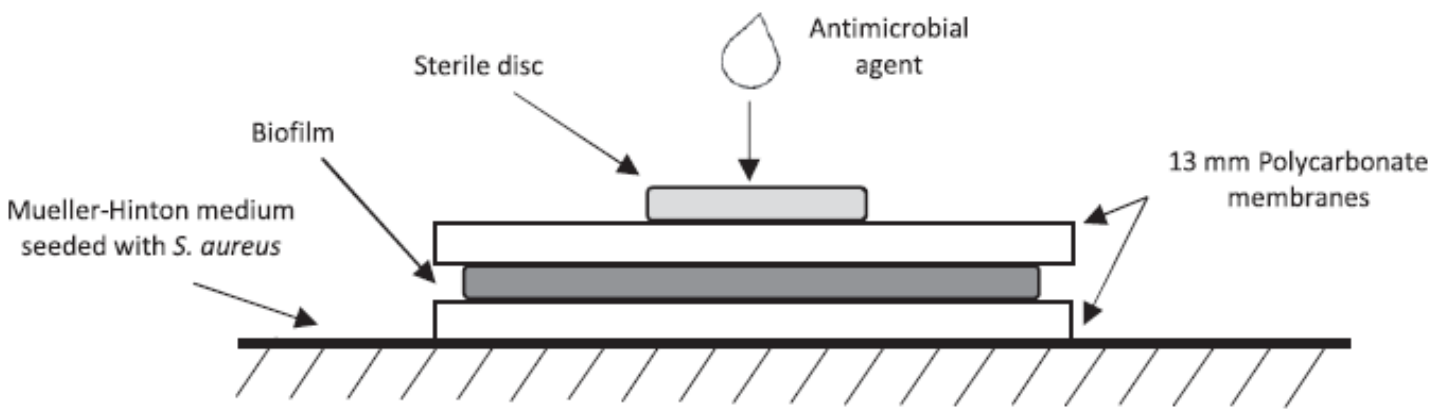

Figure 1. Array of polycarbonate membranes and biofilms for the study of the diffusion of antimicrobial agents through biofilms, Adapted from Anderl et al. (2000) and Singh et al. (2010).

\section{Biofilm formation in microtiter plates}

Biofilms were developed according to the modified microtiter plate test proposed by Stepanović et al. (2000). For each bacterium, at least 16 wells of a sterile 96-well flat-bottomed polystyrene tissue culture plate with a lid (Orange Scientific, Braine-l'Alleud, Belgium) were filled with $200 \mu \mathrm{l}$ of bacterial suspension at a density of $1 \times 109$ cells $\mathrm{ml}^{-1}$. The negative controls were wells containing culture medium without bacterial cells. The plates were incubated for $24 \mathrm{~h}$ at $30 \pm$ $3^{\circ} \mathrm{C}$ without agitation.

\section{Biofilm characterization}

Biofilms of $B$. cereus and $P$. fluorescens were removed from the polycarbonate membranes or from the microti-ter plates using a stainless steel scraper and, afterwards resuspended in $10 \mathrm{ml}$ of buffer solution ( $2 \mathrm{mM} \mathrm{Na}_{3} \mathrm{PO}_{4}, 2 \mathrm{mM} \mathrm{NaH}_{2} \mathrm{PO}_{4}, 9 \mathrm{mM} \mathrm{NaCl}$ and $1 \mathrm{mM} \mathrm{KCl}, \mathrm{pH}$ 7) and homogenized by vortexing (Heidolph, model Reax top, Schwabach, Germany) for 30 s with $100 \%$ 
power input, according to the method described by Simões et al.(2008). The homogenized biofilm suspensions were then characterized in terms of cell density, and total and extra-cellular proteins and polysaccharides. Thickness was measured for the biofilm colonies using a digital micrometer (VS-30H, Mitsubishi Kasei Corporation, Nagoya, Japan). Cell densities were assessed in terms of colony forming units (CFU) on Plate Count Agar (Merck, VWR), according to Simões et al. (2005). The biofilm suspensions were diluted to the adequate cellular concentration in buffer solution. A volume of $30 \mu \mathrm{l}$ of the diluted suspension was transferred onto PCA plates. Colony enumeration was carried out after $48 \mathrm{~h}$ at $27^{\circ} \mathrm{C}$.

To assess the total and extracellular proteins and poly-saccharides, the method described by Simões, Pereira et al. (2007) was used. Biofilm extracellular proteins and polysaccharides were extracted using Dowex resin (Frølund et al. 1996). Dowex ${ }^{\circledR}$ resin Marathon ${ }^{\circledR} \mathrm{C}$ sodium form, 20 50 mesh (Sigma, Sintra, Portugal) was added to the biofilm suspensions. The extraction took place at $400 \mathrm{rpm}$ and $4^{\circ} \mathrm{C}$ for $4 \mathrm{~h}$. The extracellular compo-nents (in the supernatant) were separated from the cells by centrifugation $(3,777 \mathrm{~g}, 5 \mathrm{~min})$. The total (before extraction) and extracellular biofilm proteins were determined using the Lowry modified kit (Sigma, Sintra, Portugal), with bovine serum albumin as standard. The procedure is essentially the Lowry et al. method (1951) as modified by Peterson (1979). The total and extracellular polysaccharides were quantified through the phenol-sulfuric acid method of Dubois et al. (1956), using glucose as standard.

\section{Biofilm control in microtiter plates}

To ascertain the adequacy of the antimicrobial penetration results for the development of biofilm control strategies, $24 \mathrm{~h}$ old biofilms formed in 96 -well microtiter plates were exposed to selected antimicrobial agents. Biofilms were exposed for $1 \mathrm{~h}$ at $30 \pm 3^{\circ} \mathrm{C}$, without agitation, similarly to the biofilm colonies. After antimicrobial exposure, the bio-films were analyzed in terms of biomass and viability and the results are presented as percentage of biofilm reduction and killing.

\section{Biomass and viability quantification}

The biomass was quantified using crystal violet (Merck VWR) staining, according to Simões, Simões et al.(2007). The bacterial biofilms in the 96-well plates were fixed with $250 \mu$ of $98 \%$ methanol (Vaz Pereira, Porto, Portugal) per well for 15 min. Afterwards, the plates were emptied and left to dry. Then, the fixed bacteria were stained for 5 min with $200 \mu$ l of crystal violet per well. Excess stain was rinsed off by placing the plate under running tap water. After the plates were air dried, the dye bound to the adherent cells was resolubilized with $200 \mu \mathrm{l}$ of $33 \%(\mathrm{v} / \mathrm{v})$ glacial acetic acid (Merck, VWR) per well. The absorbance was measured at $570 \mathrm{~nm}$ using a microplate reader (Spectramax M2e, Molecular Devices, Inc., Sunnyvale, USA). All tests were performed in three independent experiments with triplicates.

Biofilm removal was determined using Equation 1:

$$
\% B R=\frac{O D_{C}-O D_{W}}{O D_{C}} \times 100
$$


where \%BR is the percentage of biofilm removal and $O D$ is the optical density, $O D C$ is the $O_{570}$ $\mathrm{nm}$ value for biofilms not exposed to antimicrobial agents and $O D W$ is the $O D_{570 \mathrm{~nm}}$ value for biofilm exposed to the selected chemicals.

The modified alamar blue (Sigma-Aldrich) microtiter plate assay was applied to determine the bacterial viability of the cells as reported by Borges et al. (2012). For the staining procedure, fresh culture medium $(190 \mu \mathrm{l})$ was added to the plates. To each well $10 \mu \mathrm{l}$ of alamar blue (400 $\mathrm{mM}$ ) indicator solution were added. Plates were incubated for $20 \mathrm{~min}$ in darkness at room temperature. Fluorescence was measured at the wavelengths $\lambda_{\text {excitation }}=570 \mathrm{~nm}$ and $\lambda_{\text {emission }}=$ $590 \mathrm{~nm}$ with the same microplate reader. The percentage of biofilm killing was determined using Equation 2:

$$
\% B I=\frac{F I_{C}-F I_{W}}{F I_{C}} \times 100
$$

where \% $\mathrm{BI}$ is the percentage of biofilm killing, $\mathrm{FI}_{\mathrm{C}}$ is the fluorescence intensity of biofilms not exposed to antimicrobial agents and $\mathrm{Fl}_{\mathrm{W}}$ is the fluorescence intensity value for biofilms exposed to the selected chemicals.

\section{Statistical analysis}

For each parameter tested, the average and the standard deviation (SD) were calculated. The statistical significance of the results was evaluated using the paired t-test (confidence level of 95\%) with the statistical program SPSS - Statistical Package for the Social Sciences (Armonk, NY, USA), Version 20.0, to determine whether the differences between the controls and the antimicrobial tests could be considered significant.

\section{Results and discussion}

In order to ascertain possible factors involved in biofilm resistance/susceptibility to the selected antimicrobials, $B$. cereus and $P$. fluorescens biofilms were characterized in terms of their biovolume, CFU, and total and matrix pro-teins and polysaccharides (Table 2). Biofilm colonies of $B$. cereus covered $5.5 \pm 0.69 \mathrm{~mm}$ of the membrane whilst those of $P$. fluorescens covered 6.3 $\pm 0.44 \mathrm{~mm}$. B. cereus biofilms were thicker than those of $P$. fluorescens $(p<0.05)$. The cell density of $P$. fluorescens biofilms $\left(8.11 \pm 0.13 \mathrm{CFU} \mathrm{cm}{ }^{-2}\right)$ was significantly higher than for $B$. cereus $(7.20$ $\left.\pm 0.69 \mathrm{CFU} \mathrm{cm}^{-2}\right)(\mathrm{p}<0.05)$. B. cereus biofilms had greater amounts of extracellular polysaccharides and a lower extracellular protein content in comparison to those found in the $P$. fluorescens biofilm matrix $(p<0.05)$. The resulting biofilms presented larger diameters, similar thickness values, and lower cell numbers than those used in the studies of Singh et al. (2010) with S. epidermis. However, different growth conditions were used, particularly the growth period. Singh et al. (2010) used $48 \mathrm{~h}$ old biofilms while the biofilms used in this study were $24 \mathrm{~h}$ old. 
Table 2. Characterization of $B$. cereus and $P$. fluorescens grown as colonies and as microtiter plate biofilms

\begin{tabular}{lccccc}
\hline & \multicolumn{2}{c}{ B. cereus } & & \multicolumn{2}{c}{ P. fluonescens } \\
\cline { 2 - 3 } \cline { 5 - 5 } & Colony & Microtiter plate & & Colony & Microtiter plate \\
\hline Biovolume $\left(\mathrm{cm}^{3}\right)$ & $0.019 \pm 0.0023$ & & $0.018 \pm 0.001$ & \\
Log CFU cm & $7.41 \pm 0.52$ & $7.20 \pm 0.69$ & & $8.11 \pm 0.13$ & $8.89 \pm 0.34$ \\
Matrix proteins $\left(\mu \mathrm{g} \mathrm{cm}^{-2}\right)$ & $13.8 \pm 1.5$ & $16.7 \pm 0.15$ & & $20.7 \pm 0.78$ & $15.2 \pm 0.37$ \\
Total proteins $\left(\mu \mathrm{g} \mathrm{cm}^{-2}\right)$ & $49.6 \pm 2.3$ & $26.3 \pm 0.04$ & & $32.2 \pm 2.7$ & $27.1 \pm 0.02$ \\
Matrix polysaccharides $\left(\mu \mathrm{g} \mathrm{cm}^{-2}\right)$ & $20.4 \pm 2.6$ & $20.4 \pm 0.09$ & & $7.17 \pm 0.56$ & $17.4 \pm 3.0$ \\
Total polysaccharides $\left(\mu \mathrm{g} \mathrm{cm}^{-2}\right)$ & $29.8 \pm 3.1$ & $26.2 \pm 0.06$ & & $11.3 \pm 0.19$ & $23.6 \pm 2.0$ \\
\hline
\end{tabular}

Means $\pm \mathrm{SD}$ are presented.

When antimicrobial agents were applied to the biofilms, inhibition halos were produced in the S. aureus culture underneath. The size of the halos was indicative of the ability of the antimicrobial agents to penetrate the biofilms. The same characteristic is related to the antimicrobial potency of each antimicrobial agent against the $\mathrm{S}$. aureus culture, ie a larger inhibition halo was indicative of a more powerful antimicrobial agent, in terms of penetration (Table 3). In the diffusion test apparatus, ciprofloxacin and tetracycline were the antimicrobial agents that produced the largest halos (about $22 \mathrm{~mm}$ ) after passing through the biofilms of $B$. cereus and $P$. fluorescens. This behavior was closely followed by BAC and BDMDAC $(19 \mathrm{~mm}$ halos) for both types of biofilms. Erythromycin and ethanol were able to penetrate both biofilms (halos of $13 \mathrm{~mm}$ were obtained). Isopropanol, sodium hypochlorite, chlorine dioxide and streptomycin produced inhibition halos of $5 \mathrm{~mm}$. Hydrogen peroxide and CTAB caused insignificant inhibition halos $(p>0.05)$.

Table 3. Percentage killing and removal of $B$. cereus and $P$. fluorescens biofilms.

\begin{tabular}{|c|c|c|c|c|}
\hline & \multicolumn{2}{|c|}{$B$ cereus } & \multicolumn{2}{|c|}{ P. fluorescens } \\
\hline & Killing (\%) & Removal (\%) & Killing (\%) & Removal (\%) \\
\hline $\mathrm{BAC}$ & $46.6 \pm 13$ & $15.3 \pm 2.7$ & $15.5 \pm 7.5$ & $13.8 \pm 5.4$ \\
\hline CTAB & $51.8 \pm 10$ & $15.8 \pm 1.3$ & $26.5 \pm 6.9$ & $16.0 \pm 2.4$ \\
\hline Ciprofloxacin & $36.2 \pm 8.3$ & $11.8 \pm 3.7$ & $13.5 \pm 2.7$ & $22.7 \pm 8.5$ \\
\hline Streptomycin & $40.0 \pm 5.9$ & $14.3 \pm 3.5$ & $15.3 \pm 7.0$ & $16.6 \pm 1.3$ \\
\hline
\end{tabular}

Means $\pm \mathrm{SD}$ are presented.

In terms of antimicrobial retardation, values between $5 \%$ and $20 \%$ were observed for ethanol, BDMDAC and tetracycline for both biofilms, and erythromycin for $B$. cereus biofilms. Erythromycin was retarded $\sim 30 \%$ by $P$. fluorescens biofilms. The same percentage was only obtained with $B$. cereus biofilms treated with chlorine dioxide. $P$. fluorescens biofilms retarded streptomycin diffusion by $40 \%$ and isopropanol and chlorine dioxide by $50 \%$. Isopropanol was retarded by $>70 \%$ by $B$. cereus biofilms. Total antimicrobial retardation $(100 \%)$ was achieved with hydrogen peroxide and CTAB by both biofilms (for CTAB see Figure S1 [Supplementary material is available via a multimedia link on the online article webpage]), and streptomycin by $B$. cereus biofilms. The statistical analyses showed that the retardation effects of hydrogen peroxide, BDMDAC, CTAB, streptomycin and tetracycline was significant for both biofilms $(p<$ 0.05). B. cereus biofilms with isopropanol and erythromycin, and $P$. fluorescens biofilms with 
ethanol and chlorine dioxide also had significant effects on chemical retardation $(p<0.05)$. These results show that the presence of a biofilm markedly affected the diffusion of some antimicrobial agents.

Biofilms have intrinsic resistance to antimicrobial agents. Amongst those resistance mechanisms, mass transfer limitations through biofilms are especially important (Flemming \& Ridgway 2009). For the effective inactivation of bacteria in the deeper layers of a biofilms it is essential that the antimicrobial agent diffuses through the biofilm. In some cases, when biofilms are thick, cells can be in a dormant or in a low metabolic state in the deeper layer. Those cells can show substantial resistance to antimicrobials (Davies 2003; Stewart 2003). EPS protects the cells against an antimicrobial attack by hindering diffusion through the biofilm. The biofilm matrix is known to have the ability to bind to antimicrobial agents (Nikolaev \& Plakunov 2007). Anderl et al. (2000) suggested that the diffusion of anti-microbial agents might be delayed because the biofilm has the ability to chemically react with them, resulting in their inactivation. Thus, fewer antimicrobial molecules are left to interact with the deeper layers of the biofilm. Christensen et al. (2001) reported that the presence of alginate, a common EPS, caused mass transport limitations. Singh et al. (2010) reported that the biofilm phenotype provides antimicrobial resistance. These authors indicated the existence of spatial heterogeneity in the biofilm structure as a possible explanation for the poor diffusion of antimicrobial agents into biofilms. Diffusion in biofilms may be affected by charge interactions between the matrix and the antimicrobial agents, by increasing the distance between the antimicrobial agent and the bacteria, by size exclusion, and by the viscosity of the matrix (Cloete 2003). It has also been suggested that it is not the quantity of matrix that causes resistance on its own, but that its polyanionic nature hinders the antimicrobial agents (Cloete 2003). For instance, the polysaccharides can hinder antimicrobial action due to their charge and hydrophobic properties (Stewart 2003; Smirnova et al. 2010). The penetration of positively charged hydrophilic drugs is known to be delayed by the EPS matrix (Smirnova et al. 2010).

In this study, retardation percentages often differed between the types of biofilm (Table 1). Isopropanol, sodium hypochlorite and streptomycin diffused differently through the biofilms of both species. The highest retardation rates (> 70\%) occurred for $B$. cereus biofilms. The distinct retardation rates are probably due to distinct biofilm characteristics, particularly the type of EPS produced by each bacterium (Sutherland 2001). In addition, the amounts of polysaccharides and proteins produced by both types of bacteria are different. The high retardation rates observed for $B$. cereus biofilms might be related to the high protein content present (Table 2). As many antimicrobial agents target protein-like structures (McDonnell \& Russell 1999), these might be adsorbed before penetrating the biofilm.

The function of antimicrobial agents is to kill or stop the growth of an organism by biological or chemical processes (Araújo et al. 2011). The mode of action of anti-microbial agents may be another important factor contributing to mass transfer limitations through biofilms. Ethanol and isopropanol are membrane disruptors. These chemicals act by penetrating into cells through the hydrocarbon part of the phospholipid bilayer, causing rapid release of intracellular components (Maillard 2002). Even though a higher mass of isopropanol than ethanol was used, isopropanol retardation was higher, because it is slightly more reactive than ethanol against bacteria (McDonnell \& Russell 1999). Chlorine based agents are the most broadly used disinfectants (McDonnell \& Russell 1999). These chemicals are highly active oxidizing agents destroying the cellular activity of proteins. Sodium hypochlorite was slightly hindered $(<5 \%)$ by the presence of a biofilm. Oxidizing agents react strongly with cell constituents such as amino, carboxyl, 
sulfhydryl and hydroxyl groups in bacterial proteins as well as nucleic acids (McDonnell \& Russell 1999). Hydrogen peroxide damages ribosomes which are responsible for the translation of RNA into a peptide chain, and is also able to react with other cell constituents (Maillard 2002). This compound has oxidative potential, producing hydroxyl free radicals that tar-get lipids, proteins and DNA (McDonnell \& Russell 1999). Peroxides are more active against Gram-positive bacteria than against Gram-negative bacteria (McDonnell \& Russell 1999). However, the ability of both types of bacteria to produce catalase or other peroxidases may increase tolerance to this compound (Hall 1998; Anderson 2006). Quaternary ammonium compounds (QACs) are classified, according to the ionic physiognomies of their hydrophilic group, as anionic, cationic, non-ionic and zwitterionic (Atay et al. 2002). The mechanism of action of cationic surfactants (BAC, BDMDAC and CTAB) is the same as the general mechanism of QACs. The hydrophilic headgroup of QACs is adsorbed to the cell wall and reacts with the cytoplasmic mem-brane, allowing the release of intracellular constituents (Salton 1968; Ferreira et al. 2011; Trueba et al. 2013). The strong affinity of CTAB for the protein and lipid components of the membrane suggests that this QAC is spent before it reaches the under-layers of the biofilm (Simões et al. 2006). Cationic surfactants are also known to bind to DNA and DNA-protein mixtures (Gani et al. 1999). Fluoroquinolones such as ciprofloxacin are generally not hindered by the EPS of the matrix (Cloete 2003; Drenkard 2003). This was also found in the present study. The penetration of aminoglycosides (streptomycin) is known to be delayed by P. aeruginosa biofilms (Maillard 2002). Streptomycin was, in this case, $40 \%$ retarded by $P$. fluorescens biofilms and $100 \%$ when applied to $B$. cereus biofilms. This antibiotic acts by binding to prokaryotic ribosomes and has shown affinity for other nucleic acid targets (Willis \& Arya 2006). Erythromycin, a macrolide, has the same mechanism of action as streptomycin. The antimicrobial mode of action of tetracycline is by binding to ribosomes (Smythies et al. 1972). In this study, lower retardation rates were expected, since a higher mass of this compound was used (Table 1). However, it seems that this antibiotic is strongly affected by the biofilms.

The presence of inhibition halos on the $\mathrm{S}$. aureus culture is indicative of the penetration efficacy of the antimicrobial agents through the biofilms. This assay does not allow a distinction between biofilm penetration and antimicrobial potency. Taking into account the results obtained with the antimicrobial retardation tests, selected antimicrobial agents were used in order to ascertain the reliability of the results obtained with the colony biofilm system. Biofilms of $B$. cereus and $P$. fluorescens were formed in microtiter plates. The effects of BAC, CTAB, ciprofloxacin and streptomycin were assessed for biofilm removal and killing. These antibiotics and biocides had the highest and lowest retardation values. The tests were performed using 96-well microtiter plates. This bioreactor permits the assessment of biofilm killing and removal rates by the selected antimicrobial agents using a large number of replicates (Kumar et al. 2004; Stepanović et al. 2007). The biofilms developed in the 96-well microtiter plates were characterized in terms of their cell density, total and matrix polysaccharide and protein content (Table 2). The cell densities of $B$. cereus and $P$. fluorescens biofilms formed in the microtiter plates were similar to those of biofilm colonies $(p>0.05)$. Biofilm colonies had a higher amount of total proteins in comparison to those formed in microtiter plates, for both biofilms $(p<0.05)$. B. cereus biofilms had a similar poly-saccharides content in both biofilms formed as a colony and in the microtiter plates ( $p>0.05)$, while the polysaccharides of $P$. fluorescens biofilms were lower in the colony system $(p<0.05)$.

Table 3 depicts the killing and removal percentages with the selected antimicrobial agents for the biofilms formed in the microtiter plates. For $B$. cereus biofilms, removal was similar with ciprofloxacin and streptomycin (12-14\%). Their killing efficiency was statistically similar ( $p$ > 
0.05), although streptomycin was the most efficient antibiotic (40 vs $36 \%$ ). The killing percentages of $B$. cereus biofilms caused by both QACs were both $\sim 50 \%$ and removal was also similar (around 15\%). P. fluorescens biofilms were removed (17-23\%) and killed (about 15\%) equally by both antibiotics. The same biofilm was killed more easily by CTAB $(26 \%)$ than by BAC (15\%). The removal of $P$. fluorescens was similar to that verified for $B$. cereus biofilms ( 15\%). The removal and killing was significantly different between antibiotics and biocides $(p<0.05)$, which suggests that QACs are more efficient in biofilm killing than antibiotics. In general, biocides are known to perform better in the killing of biofilms, apparently due to their multitarget mode of action (Denyer \& Stewart 1998). Between B. cereus and P. fluorescens biofilms, the removal was statistically similar in all cases $(p>0.05)$. B. cereus killing was higher for both QACs and antibiotics when compared to $P$. fluorescens $(p<0.05)$. This Gram negative bacterium is known to have a higher tolerance to biocides (Paulus 1993), which is commonly explained by penetration being hindered due to the presence of the outer membrane (Maillard 2002). Between BAC and CTAB the killing percentages were not significant $(p>0.05)$.

The resistance of a biofilm is a very complex phenomenon. EPS plays an important role in antimicrobial interaction and mass transfer limitations, although other phenomena can contribute to biofilm resistance (Simões 2011; Simões et al. 2011; Borges et al. 2014). An antimicrobial agent that efficiently penetrates a biofilm does not necessarily kill the embedded cells. This means that the high penetration ability of some antimicrobial agents is not directly related to their efficiency, as indicated by the comparison between the results obtained with biofilm colonies and those formed in the microtiter plates.

In conclusion, this study uses two simple biofilm formation systems (biofilm colonies and microtiter plates) to provide insights into the role played by a biofilm in the interaction with antimicrobial agents. The systems used formed biofilms with similar characteristics in terms of CFU, proteins and polysaccharides. The overall results demonstrate that the selection of a suitable antimicrobial agent, able to penetrate a biofilm and kill the bacteria, is of utmost importance when developing disinfection plans. At the same time, a diffusion test by itself does not provide enough information on the biofilm control efficiency of an antimicrobial agent. This reinforces the fact that antimicrobial resistance in biofilms is a multi-factorial problem and transport limitations, although part of the problem, should not be implicated alone. More-over, the assessment of biofilm killing and removal is important for the selection of an appropriate control strategy. Biofilm killing and removal are distinct phenomena.

\section{Acknowledgements}

This work was supported by the Operational Programme for Competitiveness Factors [COMPETE, FCT/MEC (PIDDAC) and FEDER] through Projects Bioresist [PTDC/EBB-EBI/ 105085/2008]; and Phytodisinfectants [PTDC/DTP-SAP/1078/ 2012 (COMPETE: FCOMP-010124-FEDER-028765)]. 


\section{References}

Anderl J, Franklin M, Stewart P. 2000. Role of antibiotic pene- tration limitation in Klebsiella pneumoniae biofilm resis- tance to ampicillin and ciprofloxacin. J Antimicrob Chemother. 44:1818-1824.

Anderson D. 2006. Infections, infertility and assisted reproduc- tion. J Androl. 27:2 2.Andersson S, Dalhammar G, Land C, Kuttuva Rajarao G. 2009. Characterization of extracellular polymeric sub- stances from denitrifying organism Comamonas denitrificans. Appl Microbiol Biotechnol. 82:535-543.

Araújo PA, Lemos M, Mergulhão F, Melo L, Simões M. 2011. Antimicrobial resistance in biofilms to disinfectants. In: Méndez-Vilas A, editor. Science against microbial patho- gens: communicating current research and technological advances. Badajoz: Formatex; p. 826834.

Araújo PA, Kruithof JC, van Loosdrecht MCM, Vrouwenvelder JS. 2012. The potential of standard and modified feed spac- ers for biofouling control. J Membr Sci. 403-404:58-70.

Araújo PA, Lemos M, Mergulhão F, Melo L, Simões M 2013. The influence of interfering substances on the antimicrobial activity of selected quaternary ammonium compounds. Int J Food Sci. 9:1-9.

Atay NZ, Yenigün O, Asutay M. 2002. Sorption of anionic sur- factants SDS, AOT and cationic surfactant hyamine 1622 on natural soils. Water Air Soil Pollut. 136:55-68.

Borges A, Saavedra M, Simões M. 2012. The activity of ferulic and gallic acids in biofilm prevention and control of patho- genic bacteria. Biofouling. 28:755-767.

Borges A, Serra S, Cristina Abreu A, Saavedra MJ, Salgado A, Simões M. 2014. Evaluation of the effects of selected phy- tochemicals on quorum sensing inhibition and in vitro cytotoxicity. Biofouling. 30:183-195.

Bryers J. 1992. Mixed population biofilms. In: Melo LF, Bott TR, Fletcher M, Capdeville B, editors. Biofilms - science and technology. Dordrecht: Kluwer; p. 277-289.

Bryers J. 1994. Biofilms and the technological implications of microbial cell-adhesion. Colloid Surf B-Biointerfaces. 2:9-23.

Chapman J. 2003. Biocide resistance mechanisms. Int Biodeterior Biodegrad. 51:133-138.

Christensen B, Ertesvag H, Beyenal H, Lewandowski Z. 2001. Resistance of biofilms containing alginate-producing bacteria to disintegration by an alginate degrading enzyme (AlgL). Biofouling. 17:203-210.

Cloete T. 2003. Resistance mechanisms of bacteria to antimicrobial compounds. Int Biodeterior Biodegrad. 51:277-282.

Costerton J. 1999. Introduction to biofilm. Int J Antimicrob Agents. 11:217-221.

Davies D. 2003. Understanding biofilm resistance to antibacte- rial agents. Nat Rev Drug Discov. 2:114-122.

Denyer S, Stewart G. 1998. Mechanisms of action of disinfectants. Int Biodeterior Biodegrad. 41:261-268.

Dogan B, Boor KJ. 2003. Genetic diversity and spoilage potential among Pseudomonas spp. isolated from fluid milk products and dairy processing plants. Appl Environ Microbiol. 69:130-138.

Donlan R, Costerton J. 2002. Biofilms: survival mechanisms of clinically relevant microorganisms. Clin Microbiol Rev. 15:167-193. 
Drenkard E. 2003. Antimicrobial resistance of Pseudomonas aeruginosa biofilms. Microbes Infect. 5:1213-1219.

Dubois M, Gilles K, Hamilton J, Rebers P, Smith F. 1956. Col- orimetric method for determination of sugars and related substances. Anal Chem. 28:350-356.

Ferreira C, Pereira A, Pereira M, Melo L, Simões M. 2011. Physiological changes induced by the quaternary ammonium compound benzyldimethyldodecylammonium chloride on Pseudomonas fluorescens. J Antimicrob Chemother. 66:1036-1043.

Flemming H. 2007. The EPS matrix: the 'house of biofilm cells'. J Bacteriol. 189:7945-7947.

Flemming H, Ridgway H. 2009. Biofilm control: conventional and alternative approaches. Springer Series on Biofilms. Berlin, Heidelberg: Springer; p. 103-117.

Flemming H, Wingender J. 2010. The biofilm matrix. Nat Rev Micro. 8:623-633.

Frølund B, Palmgren R, Keiding K, Nielsen P. 1996. Extraction of extracellular polymers from activated sludge using a cation exchange resin. Water Res. 30:1749-1758.

Gani S, Chattoraj D, Mukherjee D. 1999. Binding of cationic surfactants to DNA, protein and DNA-protein mixtures. Indian J Biochem Biophys. 36:165-176.

Hall JF 1998. Methods in biotechnology. In: Biochemical education. London: Taylor \& Francis; p. 257.

Jefferson K. 2004. What drives bacteria to produce a biofilm? FEMS Microbiol Lett. 236:163173.

Kreske AC, Ryu JH, Pettigrew CA, Beuchat LR. 2006. Lethality of chlorine, chlorine dioxide, and a commercial produce sanitizer to $B$. cereus and Pseudomonas in a liquid deter-gent, on stainless steel, and in biofilm. J Food Prot. 69:2621-2634

Kumar S, Wittmann C, Heinzle E. 2004. Minibioreactors. Biotechnol Lett. 26:1-10.

Lee J-H, Cho HS, Joo SW, Regmi SC, Kim J-A, Ryu C-M, Ryu SY, Cho MH, Lee J. 2013. Diverse plant extracts and trans-resveratrol inhibit biofilm formation and swarming of Escherichia coli 0157:H7. Biofouling. 29:1189-1203.

Lindsay D, Brozel VS, Mostert JF, von Holy A. 2002. Differential efficacy of a chlorine dioxidecontaining sanitizer against single and binary biofilms of a dairy associated Bacillus cereus and a Pseudomonas fluorescens isolate. J Appl Microbiol. 92:352-361.

Lowry O, Rosebrough N, Farr A, Randall R. 1951. Protein measurement with the Folin phenol reagent. J Biol Chem. 193:265-275.

Mah T, O'Toole G. 2001. Mechanisms of biofilm resistance to antimicrobial agents. Trends Microbiol. 9:34-39.

Maillard J. 2002. Bacterial target sites for biocide action. J Appl Microbiol. 92:16s-27s.

Maukonen J, Mättö J, Wirtanen G, Raaska L, Mattila-Sand- holm T, Saarela M. 2003. Methodologies for the characterization of microbes in industrial environments: a review. $\mathrm{J}$ Ind Microbiol Biotechnol. 30:327-356.

McDonnell G, Russell A. 1999. Antiseptics and disinfectants: activity, action, and resistance. Clin Microbiol Rev. 12:147-179.

Melo L. 2005. Biofilm physical structure, internal diffusivity and tortuosity. Water Sci Technol. 52:77-84.

Nikolaev Y. 2004. Extracellular factors of bacterial adaptation to unfavorable environmental conditions. Appl Biochem Microbiol. 40:327-336. 
Nikolaev Y, Plakunov V. 2007. Biofilm - 'city of microbes' or an analogue of multicellular organisms? Microbiology. 76:125-138.

Paulus W. 1993. Relationship between chemical structure and activity or mode of action of microbiocides. In: Paulus W, editor. Directory of microbicides for the protection of materials - a handbook. Dordrecht: Kluwer; p. 9-25.

Peterson G. 1979. Review of the Folin phenol protein quantitation method of Lowry, Rosebrough, Farr and Randall. Anal Biochem. 100:201-220.

Russell A 1999. Bacterial resistance to disinfectants: present knowledge and future problems. J Hosp Infect; p. 43.

Russell A, Furr J, Maillard J. 1997. Microbial susceptibility and resistance to biocides. ASM News. 63:481-487.

Salton M. 1968. Lytic agents, cell permeability, and monolayer penetrability. J Gen Physiol. $52: 227-252$.

Sharma M, Anand SK. 2002. Characterization of constitutive microflora of biofilms in dairy processing lines. Food Control. 19:627-636.

Simões M. 2011. Antimicrobial strategies effective against infectious bacterial biofilms. Curr Med Chem. 18:2129-2145.

Simões LC, Simões M, Vieira MJ. 2007. Biofilm interactions between distinct bacterial genera isolated from drinking water. Appl Environ Microbiol. 73:6192-6200.

Simões M, Pereira M, Vieira M. 2005. Validation of respirometry as a short-term method to assess the efficacy of biocides. Biofouling. 21:9-17.

Simões M, Pereira M, Machado I, Simões L, Vieira M. 2006. Comparative antibacterial potential of selected aldehyde- based biocides and surfactants against planktonic Pseudomonas fluorescens. J Ind Microbiol Biotechnol. 33:741-749.

Simões M, Cleto S, Pereira M, Vieira M. 2007. Influence of biofilm composition on the resistance to detachment. Water Sci Technol. 55:473-480.

Simões M, Pereira M, Sillankorva S, Azeredo J, Vieira M. 2007. The effect of hydrodynamic conditions on the pheno- type of Pseudomonas fluorescens biofilms. Biofouling. 23:249258.

Simões M, Simões L, Pereira M, Vieira M. 2008. Antagonism between Bacillus cereus and Pseudomonas fluorescens in planktonic systems and in biofilms. Biofouling. 24:339-349. Simões M, Simões L, Vieira M. 2010. A review of current and emergent biofilm control strategies. LWT-Food Sci Technol. 43:573-583.

Simões LC, Lemos M, Pereira AM, Abreu AC, Saavedra MJ, Simões M. 2011. Persister cells in a biofilm treated with a biocide. Biofouling. 27:403-411.

Singh R, Ray P, Das A, Sharma M. 2010. Penetration of anti- biotics through Staphylococcus aureus and Staphylococcus epidermidis biofilms. J Antimicrob Chemother. 65: 1955-1958.

Smirnova T, Didenko L, Azizbekyan R, Romanova Y. 2010. Structural and functional characteristics of bacterial bio- films. Microbiology. 79:413-423.

Smythies J, Benington F, Morin R. 1972. On the molecular mechanism of action of the tetracyclines. Experientia. 28:1253-1254.

Spangler S, Visalli M, Jacobs M, Appelbaum P. 1996. Suscepti- bilities of non-Pseudomonas aeruginosa gram-negative non- fermentative rods to ciprofloxacin, ofloxacin, levofloxacin, D-ofloxacin, sparfloxacin, ceftazidime, piperacillin, piperacillin-tazobactam, trimethoprim-sulfamethoxazole, and imipenem. Antimicrob Agents Chemother. 40:772775. 
Stepanović S, Vuković D, Dakić I, Savić B, Švabić-Vlahović M. 2000. A modified microtiterplate test for quantification of staphylococcal biofilm formation. J Microbiol Methods. 40:175-179.

Stepanović S, Vuković D, Hola V, Di Bonaventura G, Djukić S, Ćirković I, Ruzicka F. 2007. Quantification of biofilm in microtiter plates: overview of testing conditions and practi-cal recommendations for assessment of biofilm production by staphylococci. APMIS. 115:891-899.

Stewart P. 2003. Diffusion in biofilms. J Bacteriol. 185: 1485-1491.

Stewart P. 2012. Mini-review: convection around biofilms. Bio- fouling. 28:187-198.

Sutherland I. 2001. The biofilm matrix - an immobilized but dynamic microbial environment. Trends Microbiol. 9: 222-227.

Teh KH, Flint S, Palmer J, Lindsay D, Andrewes P, Bremer P. 2011. Thermo-resistant enzymeproducing bacteria isolated from the internal surfaces of raw milk tankers. Int Dairy J. 21:742-747.

Teh KH, Flint S, Palmer J, Andrewes P, Bremer P, Lindsay D. 2012. Proteolysis produced within biofilms of bacterial isolates from raw milk tankers. Int J Food Microbiol. 157:28-34.

Traba C, Chen L, Liang D, Azzam R, Liang JF. 2013. Insights into discharge argon-mediated biofilm inactivation. Biofouling. 29:1205-1213.

Trueba A, Otero FM, González JA, Vega LM, García S. 2013. Study of the activity of quaternary ammonium compounds in the mitigation of biofouling in heat exchangers-condensers cooled by seawater. Biofouling. 29:1139-1151.

Turnbull P, Sirianni N, LeBron C, Samaan M, Sutton F, Reyes A, Peruski L. 2004. MICs of selected antibiotics for Bacillus anthracis, Bacillus cereus, Bacillus thuringiensis, and Bacillus mycoides from a range of clinical and environmental sources as determined by the Etest. J Clin Microbiol. 42:3626-3634.

Wijman JG, de Leeuw PP, Moezelaar R, Zwietering MH, Abee T. 2007. Air-liquid interface biofilms of Bacillus cereus: formation, sporulation, and dispersion. Appl Environ Microbiol. 73:1481-1488.

Willis B, Arya D. 2006. An expanding view of aminoglyco- side-nucleic acid recognition. In: Horton $D$, editor. Advances in carbohydrate chemistry and biochemistry. New York: Academic Press; p. 251-302. 